\title{
TIME VARIATIONS OF LEAD, COPPER AND CADMIUM CONCENTRATIONS IN AEROSOLS IN ANN ARBOR, MICHIGAN*
}

\author{
Paul R. Harrison, $\uparrow$ Wayne R. Matson $\ddagger$ and John W. Winchester $\S$ \\ Department of Meteorology and Oceanography, \\ The University of Michigan, Ann Arbor, Michigan 48104, U.S.A.
}

(First received 21 May 1970 and in final form 28 December 1970)

\begin{abstract}
The atmosphere in Ann Arbor, $50 \mathrm{~km}$ west of Detroit, was sampled for aerosol particles for 2-h periods over a 42-h interval Friday to Sunday, April 26-28, 1968, using a modified seven-state Andersen cascade impactor and a glass backup filter. The eight particle size fractions from each sampling were analyzed separately for lead, copper, and cadmium by means of anodic stripping voltammetry (ASV) with a composite mercury graphite electrode. Average particle size distributions were similar for the three elements over $0.1 \leqslant r \leqslant 10 \mu \mathrm{m}$, the radius range covered by the impactor stages which sort particles into factor of 2 radius intervals. $\mathrm{Pb}$, however, showed a significantly greater proportion of its total concentration in particles caught by the filter $(r \leqslant 0.1 \mu \mathrm{m})$ than did $\mathrm{Cu}$ or $\mathrm{Cd}$. Detailed differences in size distribution from sample to sample for $\mathrm{Cu}$ and $\mathrm{Cd}$ were similar and differed from those for $\mathrm{Pb}$. Substantial parallel time variations in total concentrations were seen in the ranges $6000>$ $\mathrm{Pb}>600 \mathrm{ng} \mathrm{m}^{-3}, 1000>\mathrm{Cu}>100 \mathrm{ng} \mathrm{m}^{-3}$, and $300>\mathrm{Cd}>100 \mathrm{ng} \mathrm{m}^{-3}$. Two prominent maxima were observed at 0200-2400 EST, April 27, and suggested a wind shift from north to east. The results imply that some of the $\mathrm{Cu}$ and $\mathrm{Cd}$, and much of the $\mathrm{Pb}$ at the maximum times came from the Detroit sector by easterly winds and that a 2-h sampling period is adequate for correlating changes in the environment with mesoscale meteorological parameters.
\end{abstract}

\section{INTRODUCTION}

MUCH of the analysis of urban atmospheres for lead and other trace metals has been carried out using samples collected over long time intervals and without selectivity for particle size or reference to detailed meteorological conditions. The work of LuDWIG and Robinson (1968), Lee, PATterson and WAgman (1968), and Wagman, Lee and Axt (1967) stands out because information on size distribution of several trace elements and sulfates was obtained. In the present study we have attempted to document the average mass distribution with particle size for $\mathrm{Pb}, \mathrm{Cu}$, and $\mathrm{Cd}$ in $\mathrm{Ann}$ Arbor, a town $50 \mathrm{~km}$ west of Detroit, Michigan. In addition, we have attempted to relate the measurements with short time variations in meteorological conditions by collecting samples over 2-h time intervals and making a continuous record of wind speed and direction and other meteorological parameters. We regard this work to be a feasibility study for future, more detailed investigation of the atmospheric transport of trace metals in aerosols.

\section{SAMPLE COLLECTION AND ANALYSIS}

On Friday afternoon, April 26, 1968, a modified seven-stage Andersen cascade impactor with an inline backup glass filter was attached to a Gelman Air Sampling

* Contribution No. 198 from the Department of Meteorology and Oceanography.

† Present address: Dept. of Environmental Control, 320 N. Clark Street, Room 500, Chicago, Illinois 60610, U.S.A.

* Present address: Environmental Sciences Associates, Inc., 49 Hampshire St., Cambridge, Mass. 02139, U.S.A.

§ Present address: Dept. of Oceanography, Florida State University, Tallahassee, Florida 32306, U.S.A. 
Kit placed on a platform on the roof of the East Engineering Building at the University of Michigan in Ann Arbor. The area is characterized by gently rolling terrain with little local manufacturing or power generating industry. Located $50 \mathrm{~km}$ east of Ann Arbor, the metropolitan area of Detroit shown in FIG. 1 covers an area of approximately $200 \mathrm{~km}^{2}$. It has a population of 2,000,000 persons, is heavily industrialized, and has a large amount of automotive traffic.

The sampling was carried out at 2-h intervals and terminated on Sunday afternoon, April 28. Ambient meteorological data were obtained from instruments located in the immediate proximity of the sampler.

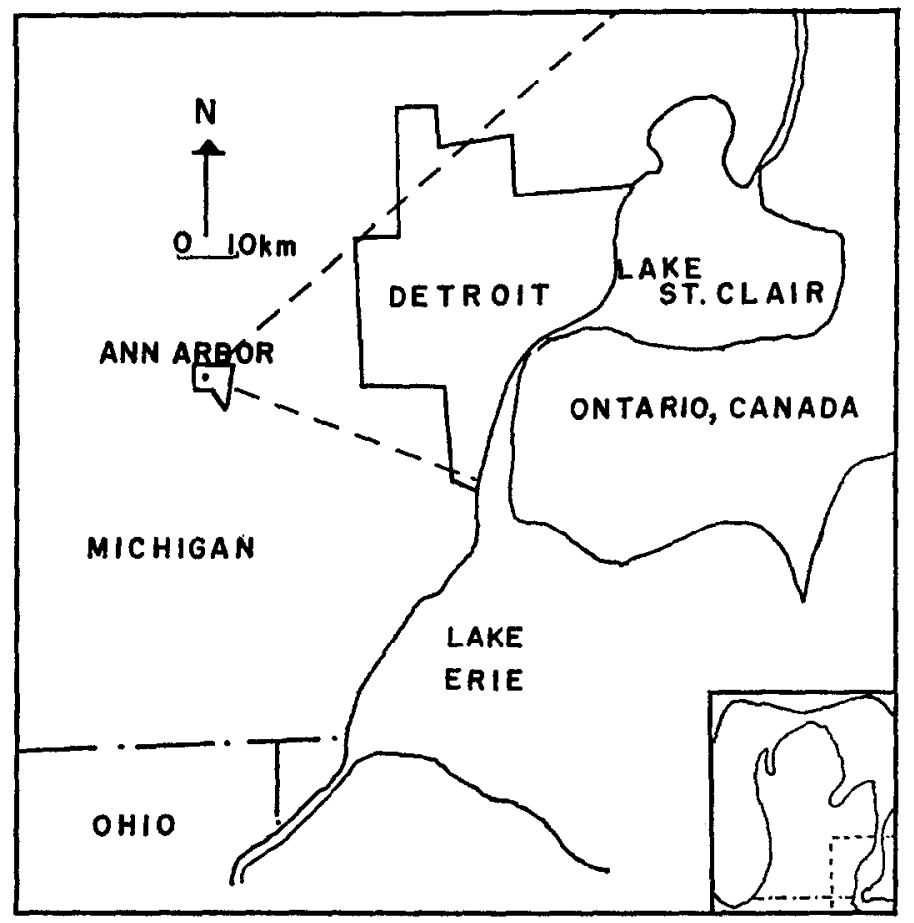

Fig. 1. Location of sampling area in relation to Detroit.

The samples were obtained on 4 mil $(0.01 \mathrm{~cm})$ thick polyethylene discs which had been precleaned by ultrasonic agitation in double distilled water, dried, and placed over the stainless steel Andersen impactor plates. One-half of each polyethylene disc was placed in a quartz cell with $10 \mathrm{ml}$ of $0.1 \mathrm{M} \mathrm{NaCl}$ which had been pre-purified over a mercury pool electrode and the sample removed from the disc by ultrasonic agitation. The sample was then analyzed on a multiple plating anodic stripping apparatus using a composite mercury graphite electrode. The cell, electrode, and apparatus have been previously described by MATSON et al. (1965) and MATSON and ROE (1967).

Successive ultrasonic agitations of the polyethylene disc with fresh solutions showed a removal efficiency of 90-97 per cent. Separate analyses of both halves of a polyethylene disc were within $\pm 5 \%$ of their average at the sample size of $200 \mathrm{ng}$. At high concentrations the major errors in the data come from the measurement of volume 
passed through the impactor with the Gelman Air Sampling Kit $( \pm 10 \%)$ and at low values from the subtraction of the variable and system carry-over blanks from the

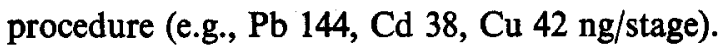

\section{METEOROLOGY}

The $24 \mathrm{~h}$ preceding the beginning of the sampling period was under the influence of a low pressure system passing to the south-east through southern Ohio and Pennsylvania, west of the Appalachians. Light rain and high humidities with fog prevailed until the afternoon of Friday, April 26. At the beginning of the sampling period, the rain and fog had moved to the east and only light cirrostratus clouds remained. By the morning of Saturday, April 27, a mesoscale high pressure area had moved into western Michigan and remained over the Michigan area throughout the sampling period. The tropospheric winds similarly decreased and remained moderate

Table 1. Meteorological data

\begin{tabular}{|c|c|c|c|c|c|c|c|c|c|c|c|}
\hline \multirow{3}{*}{$\begin{array}{c}\text { Sample } \\
\text { number }\end{array}$} & \multirow{2}{*}{$\begin{array}{r}\begin{array}{r}\text { Time } \\
\text { EST }\end{array} \\
1900\end{array}$} & \multirow{2}{*}{$\frac{\begin{array}{c}\mathrm{T} \\
(\mathrm{min})\end{array}}{111}$} & \multirow{2}{*}{$\frac{\begin{array}{r}\text { Solar } \\
\text { ins. ly. }\end{array}}{25}$} & \multirow{2}{*}{ 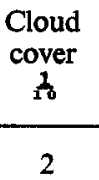 } & \multirow{2}{*}{$\begin{array}{r}\text { Temp. } \\
T\left({ }^{\circ} \mathrm{C}\right) \\
6.7\end{array}$} & \multirow{2}{*}{$\begin{array}{c}\begin{array}{c}\text { Dew pt. } \\
\operatorname{Td}\left({ }^{\circ} \mathrm{C}\right)\end{array} \\
+0.6\end{array}$} & \multirow{2}{*}{$\begin{array}{c}\begin{array}{c}\text { Rel. } \\
\text { hum. } \\
(\%)\end{array} \\
65\end{array}$} & \multicolumn{2}{|c|}{$\begin{array}{l}\text { Wind } \\
\text { speed } \Delta_{v} \\
\left(\mathrm{~ms}^{-1}\right)\end{array}$} & \multicolumn{2}{|c|}{$\begin{array}{l}\text { Wind } \\
\text { dir. } \Delta_{\theta}\end{array}$} \\
\hline & & & & & & & & 2 & 1 & 246 & 36 \\
\hline & 2206 & 107 & 0 & $\overline{0}$ & 6.1 & +0.6 & 61 & 3 & 2 & 330 & 30 \\
\hline 3 & 2405 & 104 & 0 & 0 & 5.0 & -0.6 & 69 & 3 & 1 & 75 & 15 \\
\hline 4 & 0159 & 110 & 0 & 0 & 4.4 & -0.6 & 69 & 1 & 0 & 3 & 0 \\
\hline 5 & 0400 & 110 & 10 & 0 & 2.8 & -1.1 & 74 & 2 & 1 & 330 & 0 \\
\hline 6 & 0602 & 118 & 160 & 0 & 3.9 & +0.6 & 79 & 1 & 1 & 300 & 60 \\
\hline 7 & 0825 & 85 & 430 & 0 & 8.3 & +1.1 & 61 & 2 & 1 & 280 & 60 \\
\hline 8 & 1002 & 108 & 515 & 1 & 11.7 & -3.3 & 33 & 5 & 3 & 290 & 30 \\
\hline 9 & 1201 & 110 & 625 & 1 & 13.3 & -3.9 & 30 & 5 & 4 & 310 & 30 \\
\hline 10 & 1400 & 109 & 550 & 2 & 14.4 & -3.9 & 27 & 4 & 5 & 360 & 30 \\
\hline 11 & 1600 & 109 & 280 & 1 & 14.4 & -3.3 & 29 & 4 & 3 & 360 & 30 \\
\hline 12 & 1759 & 117 & 60 & 0 & 13.3 & -3.3 & 32 & 5 & 4 & 80 & 50 \\
\hline 13 & 1959 & 110 & 0 & 0 & 7.8 & -3.3 & 44 & 3 & 2 & 90 & 90 \\
\hline 14 & 2157 & 113 & 0 & 0 & 6.1 & -3.3 & 50 & 2 & 1 & 85 & 20 \\
\hline 15 & 2357 & 113 & 0 & 0 & 5.6 & -3.3 & 51 & 3 & 1 & 70 & 15 \\
\hline 16 & 0156 & 112 & 0 & 0 & 5.0 & -3.9 & 52 & 3 & 1 & 90 & 25 \\
\hline 17 & 0355 & 115 & 0 & 0 & 4.4 & -3.9 & 52 & 4 & 2 & 112 & 72 \\
\hline 18 & 0600 & 110 & 110 & 0 & 6.7 & -1.1 & 56 & 3 & 1 & 134 & 60 \\
\hline 19 & 0759 & 113 & 400 & 0 & 10.6 & -3.3 & 38 & 4 & 3 & 134 & 120 \\
\hline 20 & 1001 & 136 & 550 & 0 & 13.3 & -3.3 & 31 & 4 & 3 & 134 & 120 \\
\hline 21 & 1223 & 121 & 570 & 0 & 14.4 & -2.2 & 31 & 4 & 3 & 150 & 180 \\
\hline
\end{tabular}

and out of the northwest. The air mass was of Continental Polar source region, and most of the residual aerosols would have been swept out of the air by the rain and fog leaving mostly recent and local material. The meteorological data and time intervals are listed in TABLE 1. As seen in FIG. 2 the temperature reflects the absence of clouds and has a smooth diurnal trace. The dew point decreased slowly during the first day and remained constant during the second except for the slight perturbation each morning after the sunrise as the ground moisture was mixed to higher elevations by heating. This phenomenon is typical in areas dominated by an anticyclone. Since relative humidity is a function of the temperature and dew point, it also follows a diurnal variation inversely proportional to the temperature. 


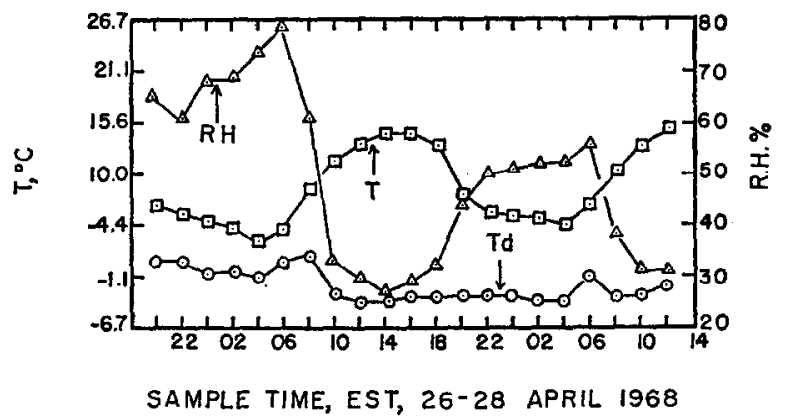

FIG. 2. Temperature $T$, relative humidity $R H$, and dewpoint temperature $T d$ vs. sample time.

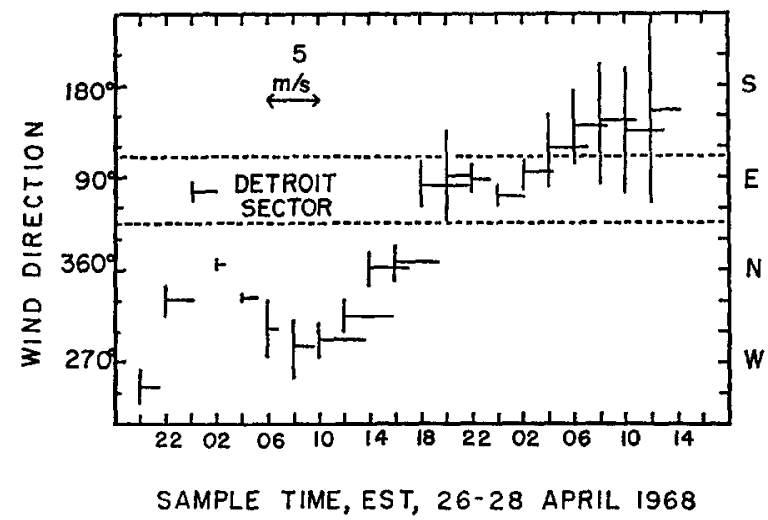

FIG. 3. Wind speed and direction vs. sample time.

The winds were light and varied slowly through the two days. In FIG. 3 the average direction is depicted by the horizontal lines whose length represents the average wind speed in meters per second. The vertical line represents the beginning of the sample time and the variation in the direction of the wind. Again, the situation is typified by low velocities and variations in the nocturnal hours and higher velocities and variability during the hours of solar insolation. The combination of the direction and the degree of variability determine the direction of our source region, and the speed determines the distance.

Under these conditions we would not expect significant contribution of trace metals from large scale advection into the area. All variations should be due to diurnal meteorological changes and/or local changes in the source regions.

\section{RESULTS AND DISCUSSION}

FIGURES 4 and 5 show the results for the variation of lead, copper, and cadmium during the period of sampling. FIGURE 4 represents the gross total concentrations without subtraction of blank for all stages of the individual samples and estimates of the maximum analytical blanks for $\mathrm{Pb}, \mathrm{Cu}$, and $\mathrm{Cd}$. In some cases the actual blank may be less, and we regard the apparent parallel variation of $\mathrm{Pb}, \mathrm{Cu}$, and $\mathrm{Cd}$ to be significant in spite of the high blank estimate for $\mathrm{Cd}$. The data indicate a variation for 


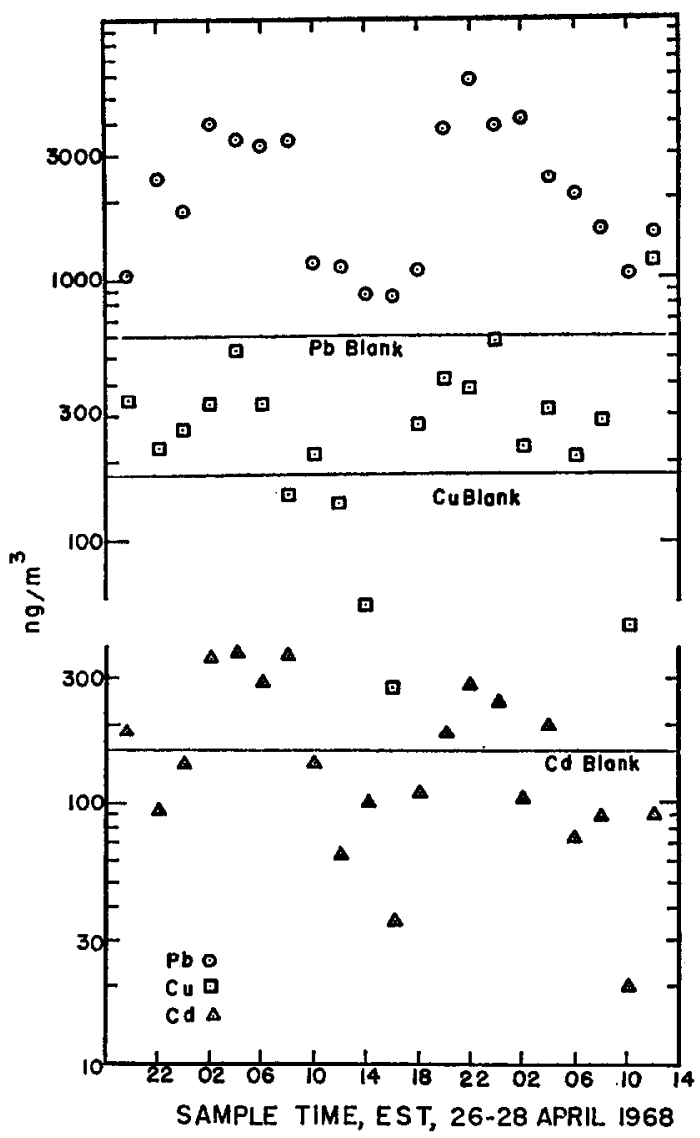

FIG. 4. Total concentrations of $\mathrm{Pb}, \mathrm{Cd}$, and $\mathrm{Cu}$ vs. time without blank subtraction and estimates of maximum average analytical blanks.

each of the elements of over a factor of ten within any $24 \mathrm{~h}$ time period during the $42 \mathrm{~h}$ represented. When initiating this experiment we expected to see some variations due to diurnal meteorological changes, but the large concentration differences in FIG. 4 seem to be best explained by non-diurnal wind variations. Maxima occurred near 0400 and again near 2200 on Saturday, April 27. The minima are approximately at 1600 Saturday and 1000 Sunday. Since the variations seem to result in maxima and minima that are not diurnal in their occurrence and since the diurnal meteorological parameters were almost identical for the two days, it may be that the major factor in these variations is wind speed and direction. By inspection of the wind direction plotted in FIG. 3 and the total concentrations plotted in Fig. 4 one can see a definite coincidence with the occurrence of the wind direction coming from the Detroit sector as shown by the dashed lines. There is an apparent phase lag of $2-4 \mathrm{~h}$.

One may also argue that the concentration variations are caused by changes in the mixing depth and diffusion characteristics. It has been shown by Moses (1969) that under certain mixing conditions the variation in concentration can be over a factor of 1000. However, the conditions present at the time were not so extreme as to suggest 


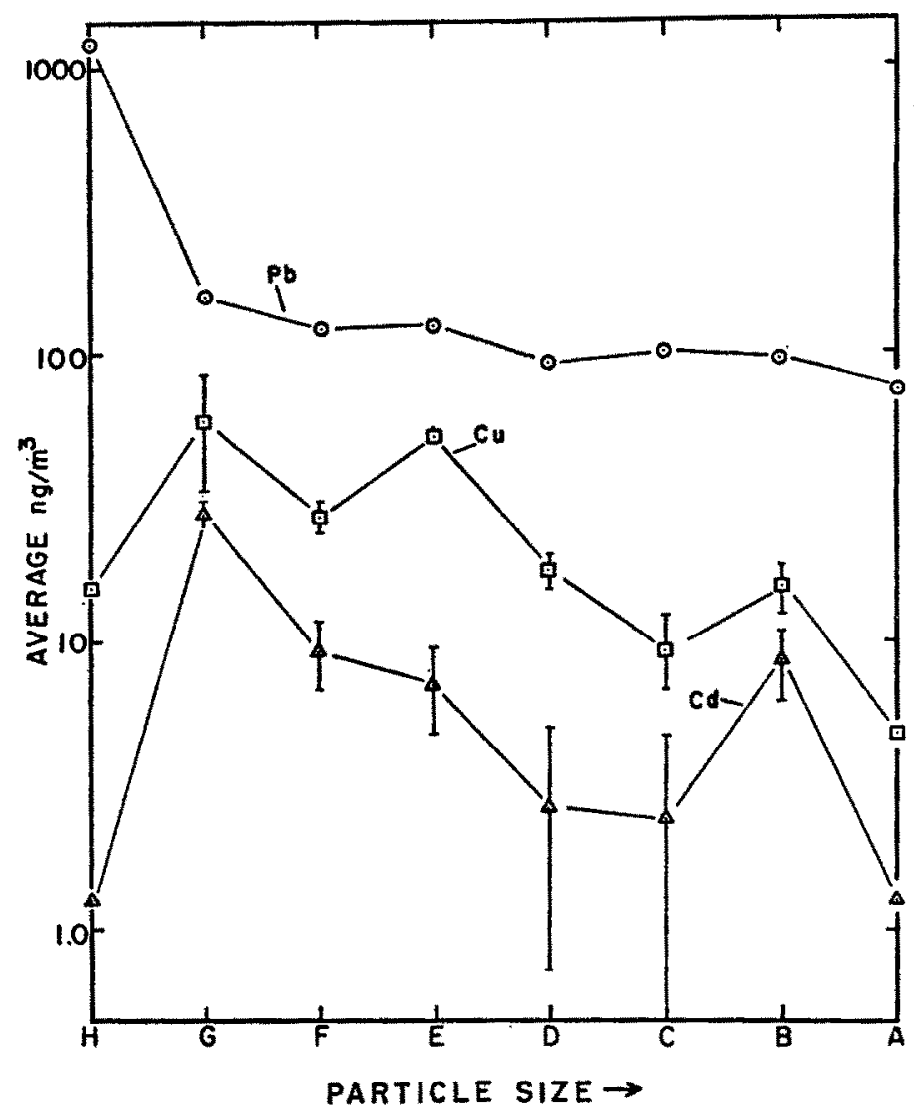

FIG. 5. Average particle size distributions of $\mathrm{Pb}, \mathrm{Cd}$, and $\mathrm{Cu}$. Concentrations are net after subtraction of analytical blanks.

that the large concentration differences found for each metal observed could be explained by simple changes in the mixing and diffusion regimes since lead must come from high concentrations of automobiles, i.e., the east sector. A much more extensive study would be required to ascertain to what extent the changes in diffusion factor would control the concentration variations.

The total concentrations seem to follow each other closely except in the later samples where cadmium departs toward lower values. Another departure comes at the first minimum at 1200 on Saturday where copper and cadmium continue to decline below the estimated maximum average blank while lead levels off to the value of about $500 \mathrm{ng} \mathrm{m}^{-3}$. This suggests that the lead is also coming from local sources or from the natural background during this minimum. One can argue that the variations are of local origin, but since lead is primarily from automobiles, and copper and cadmium are from other sources, either dependent or independent, it follows that the lead maximum comes from an area of large concentrations of autos, and there is no reason to suspect that the other elements do not advect from the same region.

The average mass distribution with particle size over the entire 42 -h sampling interval is summarized in FIG. 5. No attempt was made in this study to calibrate the Andersen 
impactor for the exact size of lead, copper or cadmium particles captured by the plates. About 60 per cent of the lead particles is below a $50 \%$ cutoff diameter of about $0.2 \mu \mathrm{m}$, in reasonable agreement with RoBINSON and LUDWIG (1967) and substantiating the hypothesis that the lead is a component of a small particle size product from high temperature combustion of tetraethyl lead in automobile engines. The copper and cadmium tend to have similar distributions with particle size and show a slight preference for the middle range of particle size.

\section{CONCLUSIONS}

From an examination of the structure of the curves in Figs. 3 and 4 it appears that a 2-h sampling period is needed but adequate for experiments concerned with the diurnal and mesoscale meteorological effects on the concentration and size distribution of aerosols. From the wide variation in concentrations over a relatively short period of time, it is apparent also that a great deal of caution must be used in interpreting the concentration of a trace element from a long period sample.

Acknowledgments-The help of D. A. GILLETTE, R. H. Loucks, and K. JoHnson on this project is gratefully acknowledged. The work was performed under Public Health Service Grant AP 00585 and NIH Air Pollution Traineeships.

\section{REFERENCES}

Lee R. E., Patterson R. K. and Wagman J. (1968) Particle size distribution of metal components in urban air. Environ. Sci. Technol. 2, 288-290.

LudwiG F. L. and RoBinson E. (1968) Variation in the size distributions of sulfur contain ing compounds in urban aerosols. Atmospheric Environment 2, 13-23.

Matson W. R., Roe D. K. and CarRIT D. E. (1965) A composite mercury graphite electrode for anodic stripping voltammetry. Anal. Chem. 37, 1598.

MAtson W. R. and ROE K. K. (1967) Trace metal analysis of natural media by anodic stripping voltammetry. Analysis Instrumentation, Vol. IV, pp. 19-22. Plenum Publ., New York.

Moses H. Urban air pollution models, to be published.

Rominson E. and Ludwig F. L. (1967) Particle size distribution of urban lead aerosols. Air Pollut. Control Ass. J. 17, 10.

WAGMAN J., LEE R. E. JR. and AXT C. J. (1967) Influence of atmospheric variables on the concentration and particle size distribution of sulfate in urban air. Atmospheric Environment 1, 479-489. 